\title{
Towards a Gamified Approach for Enhancing VBE Preparedness for Establishing Virtual Collaborations
}

\author{
Noor Jehan Rajper ${ }^{1}$, Stephan Reiff-Marganiec ${ }^{2(\bowtie)}$, \\ and Qurat-Ul-Ain Nizamani ${ }^{1}$ \\ ${ }^{1}$ Institute of Mathematics and Computer Science, \\ University of Sindh, Jamshoro, Pakistan \\ $\{$ nr76, qn\}@usindh. edu.pk \\ ${ }^{2}$ Department of Computer Science, University of Leiceter, Leicester, UK \\ srm13@le.ac.uk
}

\begin{abstract}
Formation of collaborative settings (virtual organizations, collaborative network organizations, etcetera) is hindered by the lack of trust between unfamiliar but potential partners. Gamification is the application of game design principles to non- game environments. We claim that incorporating the concepts of gamification into Virtual Organisation Breeding Environments (VBEs) leads to building trust between VBE members, as well as motivating them to be proactive members of the VBEs that contribute towards the flourishing of VBEs. This paper explores a novel gamified approach, supported by a suitable methodology, to address the relatively neglected concept of 'preparedness' of VBEs.
\end{abstract}

Keywords: Gamification - Virtual organizations - VO breeding environment • Motivation $\cdot$ Preparedness

\section{Introduction}

The organizations around the world are increasingly interested in opportunity-driven, timely and temporary collaborations and cooperation with other organizations [8]. Such collaboration, not only increase their profit but increase their survivability in today's turbulent and constantly changing business markets as well [2-4, 17]. However, different factors (such as lack of trust and the non-existence of basic infrastructure that allow for smooth transaction) play a critical role in the timely formation of such collaborations. To support this emerging tendency, long term alliances of autonomous and geographically dispersed organizations called Virtual organization Breeding Environments (VBEs) are being established among organizations, to serve as the base environments for creation of temporary and opportunity-driven collaborations [13]. Their main aim is to increase the preparedness of different organizations towards potential temporary collaborations (generally called Virtual Organizations (VOs)) [1, 11, 15]. However, in order to increase preparedness of VBEs the definition of the term must be unambiguously and formally 
defined first. At the moment, these terms mostly remain neglected and vaguely defined as per the situation.

Our hypothesis is that a deeper understanding of preparedness helps in designing applications that better capture the aspects associated with preparedness. Gamification is about capturing intrinsic innate human desires in a playful and fun way and motivating users to achieve certain objectives. We believe that it can provide great value to enhancing preparedness levels in VBEs. The main research questions that this paper addresses are:

- What does preparedness imply during different stages of VBE life-cycle?

- Who are the main players (actors) in VBEs with respect to preparedness?

- What are the behavioural characteristics of these actors in regard to their responsibilities?

The novel contributions of this paper are (a) answers to these research questions through an exploration of the feasibility of applying gamification concepts to enhance preparedness of VBEs, (b) design practices (guidelines) which enhance the preparedness depending on the stage of the VBE life-cycle and the actors involved and (c) a language to express objectives and the rules that contribute to their completion.

\section{Background}

VOs can be seen as concrete instances or configurations of partners that address a specific goal; VOs are generally seen as being created out of VBEs - which are essentially a pool of possible partners. Our aim in this work is to increase the preparedness of VBEs by tapping into the underlying behaviour shown by VBE members. We are proposing to use gamification as the solution for this matter. We now introduce the concepts of preparedness and gamification.

The success of a VBE depends on its own as well as its members' preparedness. VBE preparedness is generally defined as the agreement between members on common interests and general working principles. Interoperability between different infrastructures and processes of member organizations, provision of a basic VBE bag-of-assets to its members, and development of trust are some of the main facets [12]. The preparedness and readiness evaluation approaches suggested in the literature offer insights into evaluating VBE members suitability for a VBE and readiness to join a VO once accepted as a member.

While, preparedness of VBE members has been researched to an extent, so far focus has remained on the VBEs members only $[15,16]$. However, a great role in enhancing the preparedness is played by those who actually create and manage the $\mathrm{VBE}$ as well.

We divide VBE preparedness into two phases (with respect to the VBE life-cycle): Pre-joining and Post-joining preparedness. Pre-joining preparedness refers to preparedness of potential VBE member organizations (with intention to gain business perks by joining in) that have shown their willingness to join a VBE. Post-joining preparedness applies to existing members of VBE whether business oriented members 
or those who are running the VBE. Our work utilizes the existing work on pre-joining preparedness $[15,16]$ but focuses on exploring the post-joining preparedness.

Gamification is fast emerging as a new trend to increase user engagement, motivation and participation in any system under consideration using game tactics to non-game environments [6, 7, 18]. Gamification is used for many different purposes such as behavioural adaptation of its users, skill development, or innovation (boosting positive competition between employees, resulting in coming up with new and innovative ideas proactively from employees). Game-like elements on top of business logic aim to transform mundane, repetitive and ordinary jobs to include fun and excitement for users. Rather than changing serious application to games a very subtly addition of game-oriented elements increases the acceptability and capture user's interest in using the application, leading to benefits for the organization such as increased job performance, employee satisfaction, or greater revenue generation.

Gamification mainly comprises of three parts, game mechanics, game dynamics and game rules. To implement gamification, we need to first identify the objectives that we want to achieve using gamification. The next step is to choose gamification mechanics and dynamics. Game mechanics represent the (visual) elements that we earn as we play (perform required tasks) such as badges, points, leaderboards, virtual or real goods. Game dynamics represent the behavioural aspect that is targeted by the game rule for motivating the player to act in a certain way. When the mechanics and dynamics have been decided, game rules are devised to proceed in a game like way (such as when player $\mathrm{X}$ achieve certain points, assign it a badge).

Users can show two types of behaviour: altruistic or self-centered. Altruistic behaviour captures all forms of selfless human attributes such as philanthropy, community association, or empathy. It is generally motivated by a will to achieve something for the sake of it rather than for gain. Selfish (self-centered) behaviour includes instincts to prosper, or surpassing everybody else. The majority of game mechanics and dynamics fall into this category: usually represented through rewards for actions and symbols to show achievements (e.g. badges). Gartner suggested that by $201470 \%$ of the global 2000 organizations would have at least one gamified application ${ }^{1}$. They further predicted that out of those $80 \%$ would have failed in the coming year or so due to lack of proper thought given in identifying the objectives and the mechanics selected to achieve them ${ }^{2}$. This failure occurs as gamification mechanics and the game rules are explicitly specified by the gamification providing platforms and specification languages, but the objectives are not explicitly specified. This leads to a plethora of game rules but no easy way to tell what objectives they accomplish or what game mechanics and dynamics are used by those rules. Without this understanding observations on actions cannot easily be traced back to the right rules. Besides explicitly specifying the objectives, we should be able to identify what behavioural attributes are targeted by the game rules. Associating objective with the right behaviour will allow for devised plans to achieve the goal to be more directed and hence more likely to succeed.

\footnotetext{
1 Available at http://www.gartner.com/newsroom/id/1844115 (2011, November 9).

2 Available at http://www.gartner.com/newsroom/id/2251015 (2012, November 27).
} 


\section{Methodology and Gamified VBE Preparedness Model}

This paper explores the feasibility of providing a gamified solution for enhancing the preparedness of a VBE using gamification. We proposed the following general methodology to gamify any domain:

Step 1. Identify the main actors of the domain and the associated behavioural attributes with respect to a specific property being investigated.

Step 2. Once the domain actors have been identified identify different gamification approaches with similar characteristics as shown by actors identified in step 1 .

Step 3. Map domain actors with gamification approaches with similar characteristics.

These mappings then act as a gamified domain model with respect to certain property for a particular domain. These mappings can be used as guideline while selecting game dynamics and mechanics for the game rules in the domain to enhance the concerned property. In our case the domain is a VBE and the property being explored is "preparedness". We will now consider the steps of the methodology in this context.

Step 1: Pre-joining preparedness applies to ordinary VBE members or simply members of a VBE that have joined a VBE to gain some benefit in their respective businesses (we call these businessMembers) and post-joining preparedness applies to business members as well as member managing the VBE (the latter will be called managementMembers). managementMembers are members that have created the VBE and taken up the responsibility of day to day management and smooth running of the VBE.

Considering post-joining preparedness in more detail we can distinguish two flavours: (a) Structural preparedness and (b) Functional preparedness. Structural preparedness encompasses smooth working and management of the VBE itself such as competency management, membership management, VBE bag-of-asset management, etc. It is not of direct interest to business members themselves that take the underlying infrastructure for-granted and join the VBE for sole purpose of gaining business opportunities. It could be said that management members are altruistic in the management tasks. Functional preparedness on the other hand is of direct interest to business members as it is related to currently available and emerging businesses opportunities. Business members have joined the VBE to gain access to more business opportunities or to overcome missing resources and skills. Clearly business members are selfish.

Step 2: Having identified two kinds of actors and their predominant behaviour (selfish business members and altruistic management members), we need to explore gamification approaches. The identified guidelines will help VBE policy developers to derive appropriate game rules (including mechanics and dynamics)

Gamification is designed to target humans' intrinsic behaviour in order to motivate them to strive, engage with others, or any other purposes. As such, at first it might not 
seem natural to apply the gamification concepts to the management of alliances of different entities most of which are organizations rather than individual users. However, members in VBEs can be different entities ranging from individual users to organizations and since even the interactions between the VBE and a particular organization can be traced down to an individual user representing the organization, the gamification concepts can readily be applied to organizations as well. Earlier we identified that both altruistic and self-centered gamification behaviours exist. These map very naturally onto the identified behaviour of our actors. Altruistic behaviour can be rewarded through for example badges (which have no material value, but reflect a reward for achievement).

We also identified that game rules and objectives are not usually defined in ways that link them explicitly and obviously together. However, we are able to be explicit the specification and development of gamification objectives, the rules that satisfy or accomplish those objectives and the mechanics and dynamics of those game rules. Furthermore, we are able to rewire game rules, game mechanics and dynamics, as well as the objectives they strive to achieve during application execution.

Step 3: We now map between the concepts from step 1 and step 2. The insights gained from exploring preparedness and gamification result in the proposed gamified VBE preparedness model. This model will act as guiding principle when designing rules for specific desired VBE behaviours.

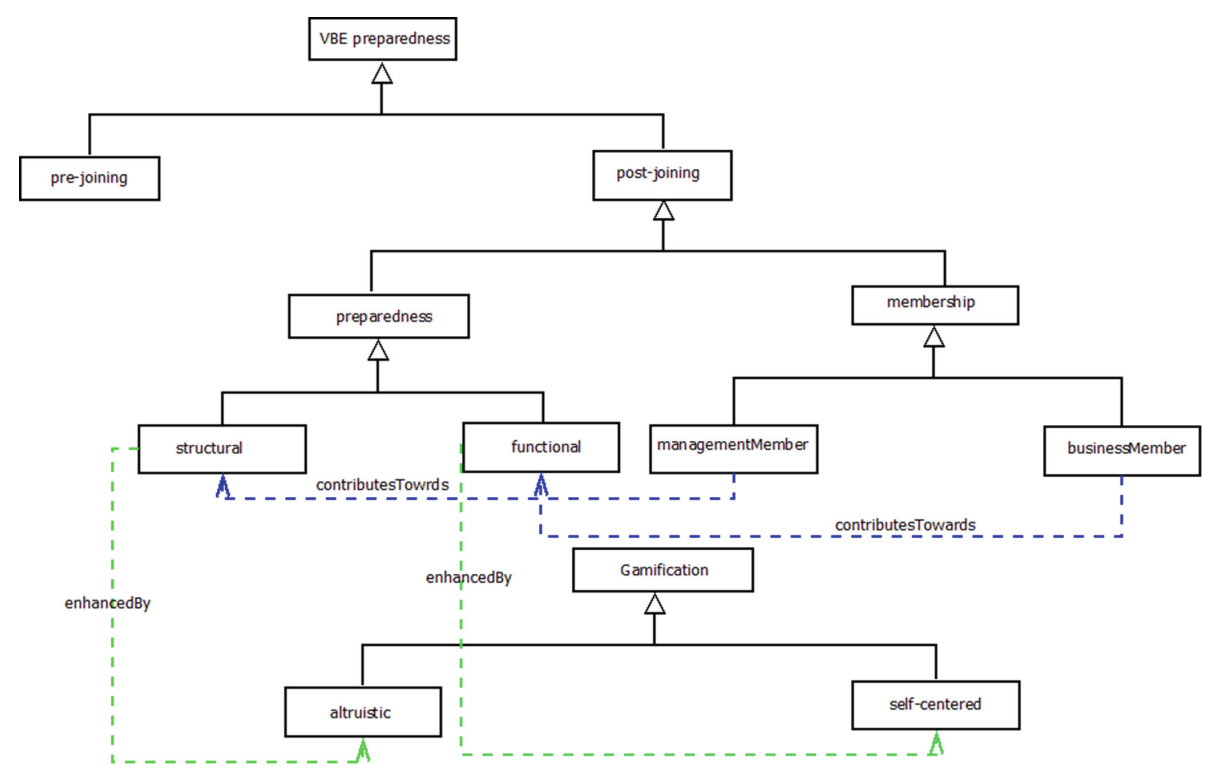

Fig. 1. Gamified VBE preparedness model

Figure 1 is a representation of the gamified VBE preparedness model. Recall that structural preparedness is for the strengthening the VBE itself and mainly the responsibility of management members which act altruistically. Therefore, the VBE 
should incorporate mechanics that raise altruistic levels for tackling the structural preparedness. The VBE will also incorporate self-centered approached to increase the functional preparedness of its business members.

\section{GPSL: Gamified Policy Specification Language}

The proposed gamified VBE preparedness model serves as a guiding principle while gamifying the VBE domain. However, we need a mechanism to specify, implement and execute the gamification concepts. The event-driven policy paradigm provides the most natural solution: we can easily add a gamification layer on top of the business logic of the domain (VBE). The policy paradigm is quite flexible and adaptable allowing for easy adaptation and change of the game rules at any time. Since, no policy language have built-in construct with concepts and elements of gamification, we have extended APPEL [14] policy language for gamification. APPEL follows the Event-Condition-Action (ECA) paradigm for policy specification. The basic building block of APPEL is a policy rule which consists of optional trigger(s), optional condition(s) and an action. A typical APPEL policy is as follows:

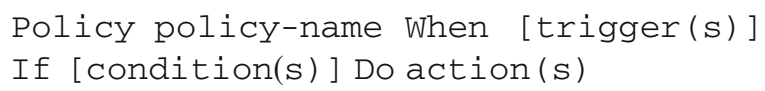

GPSL (Gamified Policy Specification Language) extends APPEL for the VBE domain through the inclusion of a VBEgoal construct. This construct allows for abstract specification of a VBE objective that is going to be achieved through gamification policies.

It has two attributes: a boolean-valued enabled attribute specifies if the VBE objective is currently enabled or disabled. If disabled, all the associated publishedBy and sinkedBy policies (explained below) are disabled as well, overwriting their localized enabled attribute. The effects attribute specifies what aspects of the VBE are going to be affected by the objective. The VBEgoal description further consists of one or more curly-bracketed blocks. Each block specifies a list of publishedBy and sinkedBy (policy references), preparedness, enabled and appliesTo attributes. The preparedness attribute specifies what preparedness category the VBE objective falls in, the enabled attribute specifies if the policies referenced by the block are currently enabled or disabled, and the appliesTo attribute describes what VBE actor type is going to be affected by the policies of the block. A typical VBEgoal looks as follow:

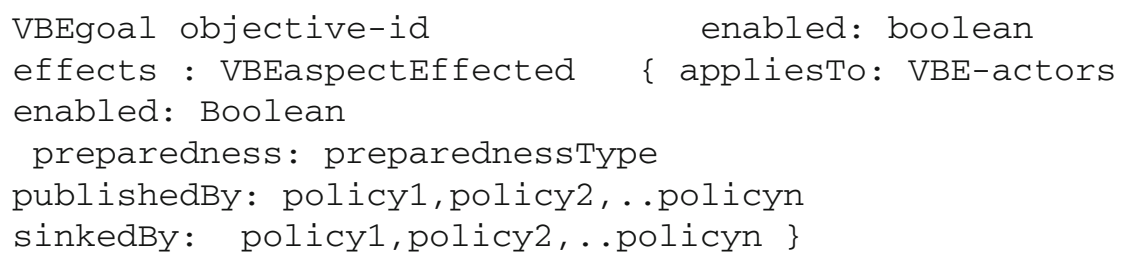


The only other construct of GPSL is the Policy construct. This construct is based on the APPEL policy rule, with one additional attribute: the supportsGoal attribute which links the policy to the VBEgoal it is contributing to.

The policies implement game rules. Each policy is either a publishing policy or sinking policy. A publishing policy is one that sets a gamified tasks for the player to accomplish, and entices them with the promise of a perk. A sinking policy is one that is triggered when the gamified task in the associated publishing policy is accomplished by the player. Whether a policy is publishing or sinking can be identified through publishedBy and sinkedBy attributes of VBEgoal description and the actions they execute.

Table 1 lists some of the actions defined by GPSL, each capturing a specific game mechanic and Table 2 lists actions for sinking policies giving a specified reward to the user. At this point, we are aware this list is incomplete and this aspect is being studied further.

Table 1. Publishing policy actions to gamify tasks

\begin{tabular}{l|l}
\hline Action & Description \\
\hline toEarnPoint (points, task) & Player is invited to earn the points, if he fulfills the task \\
\hline toEarnBadge (badge-id, task) & Player is invited to earn the badge, if he fulfills the task \\
\hline toReach (level-id, task) & $\begin{array}{l}\text { Player is informed that in his current state, he gets eligible } \\
\text { to reach mentioned level, if he fulfills the task }\end{array}$ \\
\hline $\begin{array}{c}\text { toUnlockChallenge } \\
\text { (challenge-id, task) } \\
\text { toSupportVBE }\end{array}$ & $\begin{array}{c}\text { Player is informed that the mentioned challenge can be } \\
\text { unlocked for him to play if he fulfills the task }\end{array}$ \\
\hline $\begin{array}{c}\text { toAdvanceLeaderBoard } \\
\text { (leaderboardGroup-id, task) }\end{array}$ & $\begin{array}{c}\text { The player is notified that by doing the task he is } \\
\text { contributing for the betterment of VBE and will be } \\
\text { appreciated by getting VBEhelpdBedge-id }\end{array}$ \\
\hline
\end{tabular}

Having VBE objectives explicitly specified and linking the policies that publish as well as sink the tasks associated with the objective allows to, have a structure gamified application. Instead of having a jumbled up mess of different policies, they are divided into separate groups with clear description of the purpose they serve. This allows the analysis of those policies while the application is in operation, and if the required aims are not achieved, the problematic policies can be readily identified and rectified.

The other benefit of this model is that having identified the nature of VBEgoal through its preparedness attribute, and the VBE actor type it applies to, not only helps policy developers in choosing appropriate game mechanics and dynamics, but it also contributes towards the development of policies editors that are able to suggest appropriate mechanics and dynamics to the policy developer, and in the development of automated analysis tools to assist in analysis if the chosen mechanics and dynamic contradict with the objective sought by the policies.

The concept of gamification is to make players act in a certain way without making them realize that they are actually working for some objective. The VBEgoal therefore is not visible to the player (VBE member in this case). They are only notified when a certain policy (published or sinked) applies to them and the motivation for them to act 
Table 2. Sinking policy actions to gamify tasks

\begin{tabular}{c|l}
\hline Action & Description \\
\hline $\begin{array}{c}\text { pointsEarned (points, } \\
\text { member-id/group-id) }\end{array}$ & $\begin{array}{c}\text { Mentioned points are given to the player or group of } \\
\text { players. The reasons for this rewards are not } \\
\text { specified here as sinking policies are only triggered } \\
\text { if their associated publishing policy is satisfied }\end{array}$ \\
\hline $\begin{array}{c}\text { badgeEarned (badge-id, } \\
\text { member-id/group-id) }\end{array}$ & $\begin{array}{c}\text { Player or group of players earn a badge for fulfilling } \\
\text { some criteria such as passing a threshold of points } \\
\text { specified in the associated publishing policy }\end{array}$ \\
\hline $\begin{array}{c}\text { levelReached (level-id, } \\
\text { member-id/group-id) }\end{array}$ & $\begin{array}{c}\text { Player (or group) advances to next level for satisfying } \\
\text { the task demanded by the associated publishing } \\
\text { policy }\end{array}$ \\
\hline $\begin{array}{c}\text { challengeUnlocked (challenge-id, } \\
\text { member/group-id) } \\
\text { challengeAccomplished } \\
\text { (challenge-id, member/group-id) }\end{array}$ & $\begin{array}{c}\text { The challenge gets unlocked, but the player (or group } \\
\text { of them) has to overcome it yet }\end{array}$ \\
\hline $\begin{array}{c}\text { VBESupported (hBadge-id, } \\
\text { member-id/group-id) }\end{array}$ & $\begin{array}{c}\text { Player (or group) gets some of helping VBE badge, } \\
\text { player or group of them } \\
\text { for doing the mentioned task }\end{array}$ \\
\hline $\begin{array}{c}\text { advancedLeaderBoard } \\
\text { (leaderboardGroup-id, } \\
\text { member/group-id) }\end{array}$ & $\begin{array}{c}\text { The player (or group) is advanced from its current } \\
\text { position to the next position }\end{array}$ \\
\hline
\end{tabular}

according to the policy is the promised reward or consequence mentioned in the policy. The player is blissfully kept unaware of the burden of preparedness enhancement or VBE management or its flourishing.

\section{Case Study}

The case study revolves around a VBE in the tourism sector with members with a wide diversity of competencies such as accommodation providers, travel agents, tour guides, and many others offering services such as health insurance, entertainment or telecommunications. The VBE offers its services worldwide through different VOs for different cities.

The management members are responsible for the smooth day-to-day running of VBE. As the managers of VBE they focus on facilitating the creation of new business opportunities. Though they are by default business members as well in this case study we only focus on their role as VBE management providers. Therefore, all the gamification efforts must be focused at enhancing the VBEs structural preparedness through altruistic approaches according to the model (though there can be exceptions a well).

Business members on the other hand have joined the VBE to get more business, expand their reach, overcome their shortcomings, complements their skills and resources and tap into the VBE assets. Hence, the gamified VBE preparedness described these members as self-centered and their gamification policies incorporate self-centered dynamics and enhancement of functional preparedness (again there can be 
Table 3. VBE specific list of some of GPSL triggers, conditions and actions

\begin{tabular}{|c|c|}
\hline Trigger & Description \\
\hline VOterminates (vo-id, success) & $\begin{array}{l}\text { Triggered when a VO successfully terminates } \\
\text { itself }\end{array}$ \\
\hline VOstatus (vo-id, created) & Triggered when a VO has just created \\
\hline $\begin{array}{l}\text { CompMembersRecommended } \\
\text { (managementMember-id, } \\
\text { [businessMember1-id,competency-id], } \\
\text { [businessMember2-id, competency-id])) }\end{array}$ & $\begin{array}{l}\text { Is triggered when management member } \\
\text { introduces two business members to each } \\
\text { other that have complementary } \\
\text { competencies, hence possibility for joint } \\
\text { venture in future }\end{array}$ \\
\hline $\begin{array}{l}\text { VOformedWithUnaquintedMembers } \\
\text { (vo-id, unAquinted- MemberLst) }\end{array}$ & $\begin{array}{l}\text { Triggered when the recently formed VO-id } \\
\text { has members that have no history of } \\
\text { partnership with each other(represented by } \\
\text { unAquintedMemberLst) }\end{array}$ \\
\hline $\begin{array}{l}\text { VOplannigRate (VOplanner-id, } \\
\text { threshord.below) }\end{array}$ & $\begin{array}{l}\text { Triggered when a management member's } \\
\text { (acting as VO planner) performance falls } \\
\text { below the threshold in terms of number of } \\
\text { new VO planned by him }\end{array}$ \\
\hline Condition & Description \\
\hline memberVO (VO-id, member-id) & $\begin{array}{l}\text { Returns true if member-id is (was, if has } \\
\text { terminated) member of the VO represented } \\
\text { by VO-id. }\end{array}$ \\
\hline $\begin{array}{l}\text { notAquainted (member-id, VO-id. } \\
\text { members) }\end{array}$ & $\begin{array}{l}\text { Returns true if members the VO-id are not } \\
\text { acquainted to a member-id }\end{array}$ \\
\hline friendOf (memberA, memberB) & $\begin{array}{l}\text { Returns true if memberA is a friend of } \\
\text { memberB }\end{array}$ \\
\hline $\begin{array}{l}\text { introducedBy (VO-id.memberLst, } \\
\text { member-id) }\end{array}$ & $\begin{array}{l}\text { Returns true if the member(s) (represented by } \\
\text { VO- id.memberLst) were befriended by } \\
\text { member-id }\end{array}$ \\
\hline $\begin{array}{l}\text { competencyComplements } \\
\text { ([businessMember1-id, competency-id], } \\
\text { [businessMember2-id, competency-id])) }\end{array}$ & $\begin{array}{l}\text { Returns true when the competencies of two } \\
\text { business members complement each other }\end{array}$ \\
\hline Action & Description \\
\hline $\begin{array}{l}\text { introduceFriend (VO-id.members, } \\
\text { friend-id) }\end{array}$ & $\begin{array}{l}\text { This action is an invitation to the business } \\
\text { member to which the policy applies, to } \\
\text { introduce his friend (friend-id) to his } \\
\text { partners of recently terminated VO }\end{array}$ \\
\hline recommendCompMembers() & $\begin{array}{l}\text { It is an invitation to the management member } \\
\text { to which the policy applies, to introduce } \\
\text { business members to each other if their } \\
\text { competencies complements }\end{array}$ \\
\hline
\end{tabular}

exceptions as well). Let us consider an example Scenario: Creating a sense of community and bond between members. The aim is to introduce benefits for members to introduce their trusted friends to other members to allow future VOs to be able to tap 
into more partners. Given below is the excerpt describing the objective and related publishing and sinking policies.

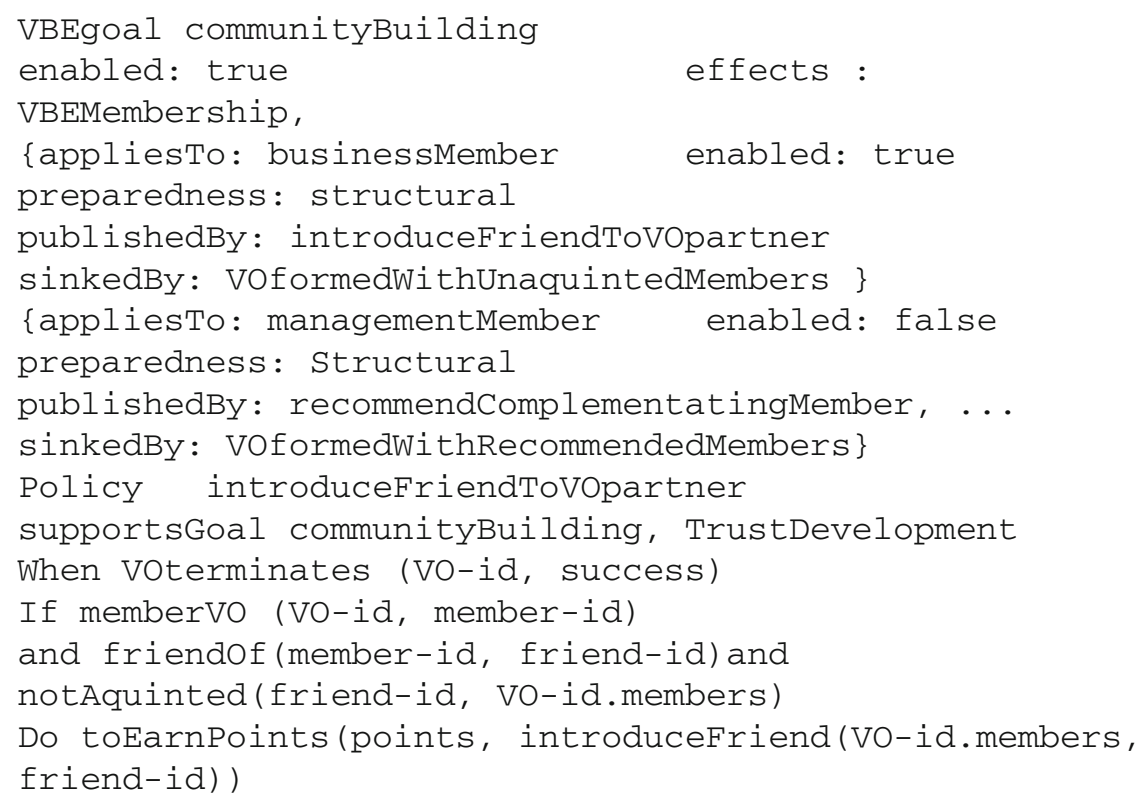

The introduceFriendToVOpartner is a publishing policy that is triggered when a VO successfully terminates. This policy invites all the members of the successfully terminated VO to introduce their friends to the members of the recently terminated VO with the promise of gaining certain points when this acquaintance is realized in the form of new VO creation with at least one of the members from terminated VO and the newly acquainted friend.

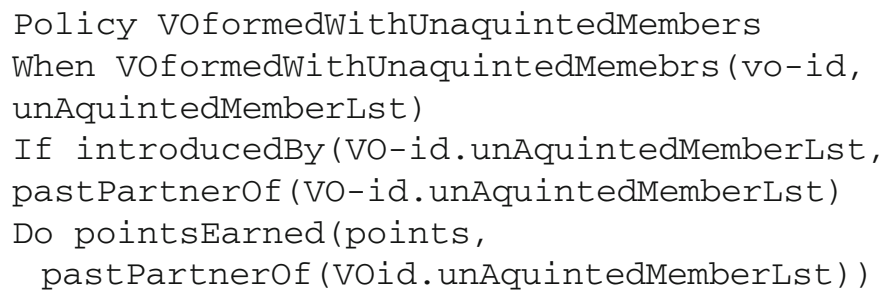

The policy, VOformedWithUnaquintedMemebrs is a sinking policy that is triggered when a new VO is formed that has members that are doing business together for the first time. Once the policy is triggered, its associated condition is checked which in this case checks if the unacquainted members were introduced (befriended) to each 
other by their common friend (i.e. VO-pastPartnerOf(id.unAquintedMemberLst)). If that happens to be the case, the common friend is rewarded (pointsEarned() action).

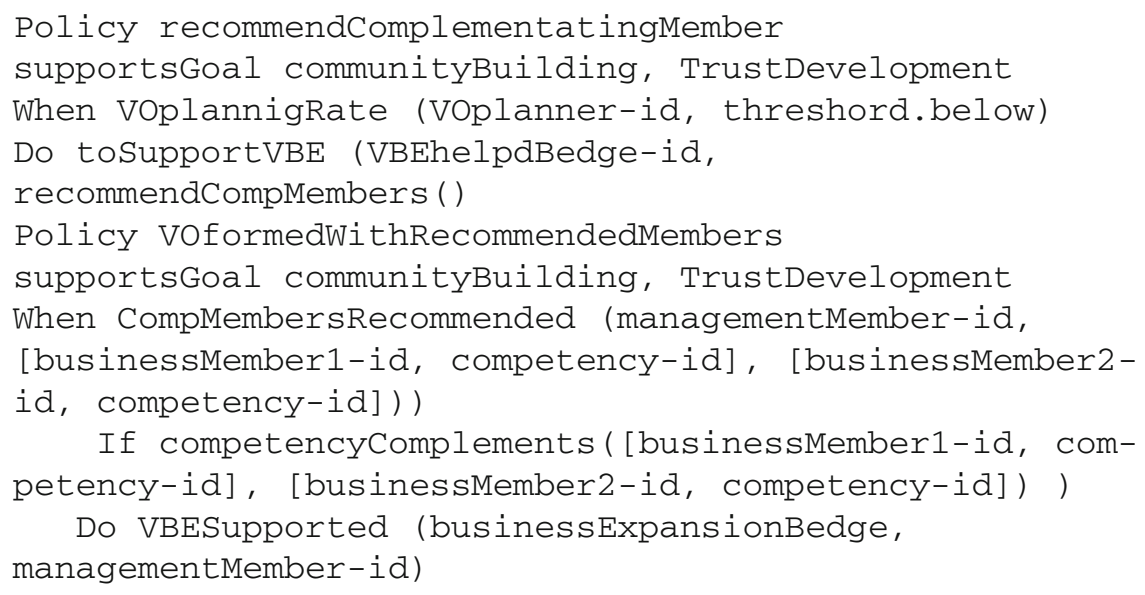

Table 3 shows some of the VBE specific triggers and actions as used in the scenario. As can be seen from the case study, relatively complex constructs in terms of describing preparedness for VBEs - namely descriptions of how behaviour can be introduced through objectives that increase preparedness (here through having better links between possible partners as well as a wider field of available partners) can be readily captured in a goal description. More importantly, that goal description is linked to clear operational rules that describe how the goal is achieved.

\section{Related Work}

VBE preparedness has been rightfully acknowledged as one of the core benefits of VBEs [13, 15, 16]. In [15, 16], preparedness of potential VBE members has been discussed in depth. However, it mostly applies to evaluating business members (in our context) inclusion into a VBE. We attempt to further our current understanding of preparedness, in particular what it implies, once the business member has been added to a VBE as well as preparedness to members managing the VBE and the role of preparedness in the operational phase of a VBE.

Gamification is has been applied in different domains recently [5, 9, 19], but most of the applications target individual users (players) using the application. In this paper we have shown that gamification concepts can be trivially applied to situations where target players are actually organizations and not just an individual. Other aspects that distinguish our work from the current gamification implementation approaches is that current solutions do not explicitly specify the objective that is to be achieved through different game rules [10]. This has serious consequence when the size of the application grows, as it becomes increasingly difficult to identify what game rules are trying to 
achieve and which game rules collective achieve an objective. Our small policy based modelling language revolves around specifying game rules (policies) for an explicitly specified objective.

\section{Conclusion and Future Work}

In this paper we put forward a gamified model for enhancing the preparedness of VBEs. This model is obtained by following a methodology proposed in the paper: First of all we identify different actors of a VBE with respect to behaviour that emerges out of the type of responsibilities assigned to them. Then, gamification approaches are explored that relate to the behaviour of the different actors identified previously. This allows us to associate VBE roles to gamification approaches with similar behavioural characteristics. To gamify the VBE application we defined GPSL, a policy language capturing specific game mechanics. The GPSLs unique approach to explicitly specifying VBE objectives to be gamified and linking them with respective publishing and sinking policies have two immediate benefits: (1) the VBE objective is explicitly specified thus the purpose of the policies is immediately visible and (2) policies can be grouped with respect to the objectives they are contributing to.

In future, we will further validate our gamified VBE preparedness model against different VBEs to verify its applicability beyond the current case study. Other direction we are intending to investigate further are, applying the proposed methodology to develop gamified models for other domains. We are also investigating development of tools that suggest game dynamics for an objective at hand while designing policies that contribute towards achieving it.

\section{References}

1. Afsarmanesh, H., Camarinha-Matos, L.M., Msanjila, S.S.: On management of 2nd generation virtual organizations breeding environments. Ann. Rev. Control 2(33), 209219 (2009)

2. Camarinha-Matos, L.M., Afsarmanesh, H.: Creation of virtual organizations in a breeding environment. In: Proceedings of INCOM 6 (2006) 12th IFAC Symposium on Information Control Problems Manufacturing, Saint-Etienne, France, 17-19 May 2006

3. Camarinha-Matos, L.M., Afsarmanesh, H.: A framework for virtual organization creation in a breeding environment. Ann. Rev. Control 1(31), 119-135 (2007)

4. Camarinha-Matos, L.M., Afsarmanesh, H., Ollus, M.: Ecolead: a holistic approach to creation and management of dynamic virtual organizations. In: Camarinha-Matos, L.M., Afsarmanesh, H., Ortiz, A. (eds.) Collaborative Networks and Their Breeding Environments, pp. 3-16. Springer, New York (2005)

5. Crowley, D.N., et al: Gamification of citizen sensing through mobile social reporting. In: IEEE International Games Innovation Conference (IGIC) 2012. IEEE (2012)

6. Deterding, S.: Gamification: designing for motivation. Interactions 4(19), 14-17 (2012)

7. Deterding, S., et al: Gamification: using game-design elements in non-gaming contexts. In: CHI 2011 Extended Abstracts on Human Factors in Computing Systems. ACM (2011) 
8. Foster, I., Kesselman, C., Tuecke, S.: The anatomy of the grid: enabling scalable virtual organizations. Int. J. High Perform. Comput. Appl. 3(15), 200-222 (2001)

9. Hamari, J.: Transforming homo economicus into homo ludens: a field experiment on gamification in a utilitarian peer-to-peer trading service. Electron. Commer. Res. Appl. 4 (12), 236-245 (2013)

10. Herzig, P., et al: GaML-a modeling language for gamification. In: Proceedings of the 2013 IEEE/ACM 6th International Conference on Utility and Cloud Computing. IEEE Computer Society (2013)

11. Irigoyen, J., et al.: Virtual breeding environment: working and sharing principles. In: Konstantas, D., Bourrières, J.P., Léonard, M., Boudjlida, N. (eds.) Interoperability of Enterprise Software and Applications, pp. 99-110. Springer, London (2006)

12. Kasper-Fuehrera, E.C., Ashkanasy, N.M.: Communicating trustworthiness and building trust in interorganizational virtual organizations. J. Manag. 3(27), 235-254 (2001)

13. Sánchez, N.G, Apolinar, D., Zubiaga, G., Atahualpa, J., González, I., Molina, A.: Virtual breeding environment: a first approach to understand working and sharing principles. In: Proceedings of First International Conference on Interoperability of Enterprise Software and Applications INTEROP-ESA (2005). http://interop-esa05.unige.ch/INTEROP/Proceedings/ Interop-ESAScientific/PerPaper/I04-1\%20456.pdf

14. Reiff-Marganiec, S., Turner, K.J., Blair, L.: Appel: the accent project policy environment/language. Technical report, TR-161, University of Stirling, December 2005

15. Romero, D., Galeano, N., Molina, A.: Mechanisms for assessing and enhancing organisations readiness for collaboration in collaborative networks. Int. J. Prod. Res. 17 (47), 4691-4710 (2009)

16. Rosas, J., Camarinha-Matos, L.M.: Modeling collaboration preparedness assessment. In: Camarinha-Matos, L.M., Afsarmanesh, H. (eds.) Collaborative Networks: Reference Modeling, pp. 227-252. Springer, New York (2008)

17. Sadigh, B.L., Unver, H.O., Nikghadam, S., Dogdu, E., Ozbayoglu, A.M., Kilic, S.E.: An ontology-based multi-agent virtual enterprise system (omave): part 1: domain modelling and rule management. Int. J. Comput. Integr. Manuf. 1-24 (2016)

18. Deterding, S., et al: From game design elements to gamefulness: defining gamification. In: Proceedings of the 15th International Academic MindTrek Conference: Envisioning Future Media Environments. ACM (2011)

19. Simes, J., Redondo, R.D., Vilas, A.F.: A social gamification framework for a K-6 learning platform. Comput. Hum. Behav. 2(29), 345-353 (2013) 